\title{
On narrative (re)imagining in the age of pandemic: Editor's Introduction
}

\author{
Mariaelena Bartesaghi \\ University of South Florida, Tampa, Florida
}

This issue, that has been realized and published during the difficult period of the global pandemic, is the result of many efforts and for this I would like to thank the editorial team and all the wonderful contributors, readers and reviewers of Qualitative Research in Medicine \& Healthcare. This issue opens with a beautiful piece on narrative as aesthetic re-imagining and closes with an article on telemedicine, taking us through both a historical and symbolic timeline of our how the stories of our lives have changed as the authors' submissions illuminate the synchronicities of the human condition and the unexpected challenges of healthcare (and the process of academic publishing!). In recognition of the experiences in our embodied and semiotic experiences, and the incarnate narratives of healthcare, we are inviting manuscripts for a special issue on COVID-19 guest edited by oncologist, author and playwright Lodovico Balducci, MD. We hope many of you will contribute. The call, with a deadline of December 1, is posted below.

The four excellent articles in this issue are connected by the idea of narrative as a way in and a way out, a way to understand the healthcare experience and a way to re-create (re-search in the literal meaning of the term) an understanding of what could be. The impeccably researched and beautifully written opening article by Stephanie Pangborn and Lynn M. Harter, Traversing temporalities at end-of-life: Mobilizing narratives with imagination and aesthetic sensibilities is especially touching to me, for it proves that we are all characters in each other's narratives. One year and 20 days ago, I watched my best friend die. Arguably, she died after years of living with metastatic cancer that had now visibly spread to her neck, rising to the surface like pebbles at

Correspondence: Mariaelena Bartesaghi, Associate Professor, Communication, University of South Florida CIS 1040, 4202 E. Fowler Ave, Tampa, FL 33620, USA; Editor-in-Chief, Qualitative Research in Medicine and Healthcare.

E-mail: mbartesaghi@usf.edu

Received for publication: 18 August 2020.

Accepted for publication: 25 August 2020.

This work is licensed under a Creative Commons Attribution NonCommercial 4.0 License (CC BY-NC 4.0).

${ }^{\circ}$ Copyright: the Author(s), 2020

Licensee PAGEPress, Italy

Qualitative Research in Medicine \& Healthcare 2020; 4:I-II

doi:10.4081/qrmh.2020.9314 low tide. But I saw her die in the oncologist's office on the day of her last visit, when the doctor told her the story of her life as a cancer patient was over, and she had run out of options. I was there as her surrogate and advocate, to tell the oncologists that treatments might be still available, but the oncologist would not budge. I watched my friend, already very weak, slump in her wheelchair, as I told her not to give up, but she was already gone. She asked me not to blame her for giving up.

For the next three weeks, however, she lived anew in hospice. Her family, who had previously chosen to ignore the gravity of her situation, chose to finally come by her bedside. They held her. While she slept in the bedroom with her morphine drip, they sat together in the living room, talking as they had not in years, looking at boxes of her old photographs, reconstructing her life in novel ways. "Look at my mother", one of her sons said to me, showing me a photo of my friend as I had never seen her, with long hair "she is so gorgeous". "Yes, she is". My best friend died in the plot of a different story than the one in which she had lived the last years of her life as a cancer patient: imagining that her children would find their way, and that the conflicts between them were somewhat abated. I asked her forgiveness for not allowing this story, the story of her hospice death, to unfold sooner. In their analysis of how narratives at the end of life can reach beyond language to the sensate experiences that are intense and unspeakable, Pangborn and Harter encourage healthcare practitioners to realize that

"Language is limited. Life and its ending are confusing, chaotic, and messy journeys but they are also beautiful, experienced and expressed in vivid ways. Our stories should reflect this reality. Our relational choices, personal and professional, should have the courage, the audacity, to embrace imagination as a narrative sensemaking resource that is responsive to life's inherent fragility and vulnerability". ${ }^{1}$

As I see it, Nykanen and Mikkola's study of The Discursive Struggles of the Client-Worker Relationship in Social Services also attends to narrative, and in this instance how locally produced accounts fit into the social narratives of social work. By analyzing social workers' everyday professional tensions as a dialogue or dynamic inter-action between what is and what is imagined about or expected from them by clients and tropes about the profession, the authors take the first step in reconciling the relational schisms and ruptures experienced by all parties engaged in social services. This is an important step toward encouraging a novel sensemaking about the social work profession by way 
of voicing the inherent contradictions of its practice.

For several years now, the story in medicine and in the Media has been that we are in the midst of what Cataldo, Collins, Mckinnies, Nichols, and Shaw write about, namely, an opioid epidemic. As someone who suffers from disabling fibromyalgia and is now personally involved in what only a few years ago I thought was a distressing social situation that would have nothing to do with me, I found Addressing the Opioid Epidemic: Recommended Solutions from Physicians a fascinating article. I am glad the authors present the difficulties encountered by physicians as they face more and more scrutiny, and as their compassion is challenged by strict regulations imposed to curtail the problems caused by the unrestrained prescribing practices of the recent past. And yet I also wonder, as someone who used to refuse pain medication even after surgery and now cannot remember life without pain, if physicians (including those interviewed) have any idea what pain feels like. What if the opioid epidemic were reimagined as an entirely different narrative from that told in medical terminology? What if it could be seen in the faces and bodies of those who are suffering and often referred to as drug seekers or addicts? Opioids barely make a dent in my pain and they are certainly not what I "seek". More studies such as this are necessary to urge physicians to think of solutions but also to think narratively and dialogically, so that the story of finding solutions could be retold together with those who are desperate for relief from pain.

The closing article brings us to the present time, as many of us are engaged at either end of telehealth - as healthcare professionals, patients and clients in the midst of a pandemic. But Rahman, Keenan and Hudson's Exploring rural palliative care patients' experiences of accessing psychoso- cial support through telehealth: A longitudinal approach is not about COVID-19, but rather about delivering art therapy to palliative care cancer patients who, by virtue of their physical and geographical limitations would otherwise not have access to a therapist. The study therefore gives the "sense of an ending" to the opening article, by coming full circle in a synchronicity between narrative and life. Rahman, Keenan, and Hudson find that virtual communication is in no way less than its face to face counterpart (as many of us would be guilty of believing). In fact, the affordances of the screen as a site of engagement between therapist and patient allows for different "states of talk" to unfold, where the screen was not a barrier, but a shield of "comforting invisibility" and "the ability to choose whether the therapist was visible or not created the freedom to just talk. ${ }^{3}$

Together with social distancing, the term unprecedented comes up a lot lately. This is a time of unprecedented loneliness. The authors of this issue, each in their own way, invite us to challenge tired assumptions, and enter into novel spaces of dialoguing, thinking, feeling, sensing.

\section{References}

1. Pangborn, S, Harter L. Traversing temporalities at end-oflife: Mobilizing narratives with imagination and aesthetic sensibilities. Qualitative Research in Medicine and Healthcare 2020;4:8642.

2. Jones R. Spoken Discourse. Bloomsbury Academic; 2006.

3. Rahman RJ, Keenan J, Hudson J. Exploring rural palliative care patients' experiences of accessing psychosocial support through telehealth: A longitudinal approach. Qualitative Research in Medicine and Healthcare 2020;4:8821.

\section{CALL FOR PAPERS \\ Qualitative Research in Health and Medicine, Special Issue on Living Through COVID-19}

\section{Special Issue Guest Editor: Lodovico Balducci, MD, Moffitt Cancer Center}

The median age in the USA is 38. This means that half of the population was born on or after 1982. For most Americans and Western Europeans, the epidemics of Asian Influenza is remote history. Even the memory of those few who were alive is tainted by the limited medical science and resources of the time. Suffice it to say that the structure of the DNA had been defined only one year prior to the Asian, that viruses were mostly the product of imagination, that Intensive Care Units were unknown, clinical epidemiology was unsophisticated and the population was much younger and at a lesser risk of dying. So, the epidemics of COVID19 is for everybody a new and novel experience.

The goal of this special issue of Qualitative Research in Medicine and Healthcare is to bring forth the lived experience of the coronavirus. In particular we will focus on two interwoven aspects. The experience of health professionals and academics affected by the disease, and how the pandemic has influenced our research, our priorities, our practices, faith, our constructs of justice, health, safety, and love.

The basic question we plan to address is: what is it like to practice medicine at a time of uncertainty and ongoing death? Evidence-based studies are completely inadequate and only the description of personal experience may provide guidance to accept uncertainty. That is when literature and art become an investigative tool. It is the time of qualitative research.

Due date December 1, 2020.

For questions feel free to contact the editor, Mariaelena Bartesaghi: mbartesaghi@usf.edu or the guest editor, Lodovico Balducci: lodovico.balducci@moffitt.org http://pagepressjournals.org/index.php/qrmh/index 